\title{
Cellular Localization of Two Rickettsia Symbionts in the Digestive System and within the Ovaries of the Mirid Bug, Macrolophous pygmaeus
}

\author{
Maria Dally ${ }^{1,2}$, Maya Lalzar ${ }^{3}$, Eduard Belausov ${ }^{4}$, Yuval Gottlieb ${ }^{5}$, Moshe Coll ${ }^{1}$ and \\ Einat Zchori-Fein ${ }^{2, *}$ \\ 1 Department of Entomology, RH Smith Faculty of Agriculture, Food and Environment, The Hebrew \\ University of Jerusalem, POB 12, Rehovot 7610001, Israel; maria.dally@mail.huji.ac.il (M.D.); \\ moshe.coll@mail.huji.ac.il (M.C.) \\ 2 Department of Entomology, Newe-Ya'ar Research Center, ARO, Ramat-Yishay 30095, Israel \\ 3 Bioinformatics Service Unit, University of Haifa, Haifa 3498838, Israel; maya.lalzar@gmail.com \\ 4 The Institute of Plant Sciences, The Volcani Center, ARO, HaMaccabim Road, Rishon LeZion 7528809, Israel; \\ eddy@agri.gov.il \\ 5 Koret School of Veterinary Medicine, The Hebrew University of Jerusalem, POB 12, Rehovot 76100, Israel; \\ gottlieb.yuval@mail.huji.ac.il \\ * Correspondence: einat@agri.gov.il
}

Received: 19 July 2020; Accepted: 11 August 2020; Published: 13 August 2020

check for updates

Simple Summary: Like most insects, those that feed on both prey and plant materials harbor symbiotic bacteria in their body. Yet the involvement of bacteria in the feeding habits of these omnivorous consumers has yet to be investigated. In the present study, we took the first step toward testing the hypothesis that bacterial symbionts are involved in the feeding habits of the omnivorous bug Macrolophus pygmaeus. We (I) characterized the microbiome (the assembly of bacteria and fungi) of M. pygmaeus, and (II) determined the identity and location of the most dominant bacteria species within the host body. We found that M. pygmaeus microbiome is dominated by two Rickettsia species, $R$. belli and R. limoniae. These bacteria are found in high numbers in the digestive system of the bug, each exhibiting a unique distribution pattern, and for the most part, do not share the same cells in the gut. These results strongly suggest that the host bug may gain some nutritional benefits by hosting the two dominant symbiotic bacteria in its gut.

\begin{abstract}
Bacterial symbionts in arthropods are common, vary in their effects, and can dramatically influence the outcome of biological control efforts. Macrolophus pygmaeus (Heteroptera: Miridae), a key component of biological control programs, is mainly predaceous but may also display phytophagy. M. pygmaeus hosts symbiotic Wolbachia, which induce cytoplasmic incompatibility, and two Rickettsia species, R. bellii and R. limoniae, which are found in all individuals tested. To test possible involvement of the two Rickettsia species in the feeding habits of M. pygmaeus, we first showed that the microbiome of the insect is dominated by these three symbionts, and later described the distribution pattern of the two Rickettsia species in its digestive system. Although both Rickettsia species were located in certain gut bacteriocyes, in caeca and in Malpighian tubules of both sexes, each species has a unique cellular occupancy pattern and specific distribution along digestive system compartments. Infrequently, both species were found in a cell. In females, both Rickettsia species were detected in the germarium, the apical end of the ovarioles within the ovaries, but not in oocytes. Although the cause for these Rickettsia distribution patterns is yet unknown, it is likely linked to host nutrition while feeding on prey or plants.
\end{abstract}

Keywords: bacteriocyte; bacterial microbiome; FISH; omnivory 


\section{Introduction}

Colonization by microorganisms is a universal phenomenon among animals including insects, one of the most successful groups in the animal kingdom [1]. Various types of symbiotic associations with microorganisms including fungi, viruses, protozoans, and particularly bacteria, have contributed to this success. Indeed, bacterial associations are widespread throughout the Insecta [2,3]. In recent decades, the working definition of a symbiont has been expanded to include all microbes that colonize animals, making up the host microbiome [4]. The insect microbiome is a dynamic microbial community which shapes many life history traits of its host [5]. Some symbiotic bacteria, for example, induce sex ratio distortion through mechanisms such as male killing, parthenogenesis, feminization, or cytoplasmic incompatibility [6]. Since microbiota account for up to $1-10 \%$ of the biomass of insects [3], they have become the focus of intense research.

Bacterial symbionts can generally be divided into two main categories: inherited intracellular symbionts, which are vertically transmitted from one host generation to the next, and extracellular symbionts, which are acquired from the environment [7]. Symbionts can also be categorized as either obligatory for the survival and development of their hosts, in that they provide digestive capabilities or supplement the hosts' diet with essential nutrients, or facultative, influencing host fitness by altering host traits and capabilities [8].

It has been suggested that symbionts may be involved in determining the range of food sources that the host is able to exploit [9]. For instance, in the facultative seed-eating predatory beetle Harpalus pensylvanicus (Carabidae), more seeds from Chenopodium album were consumed in the presence of the symbiont Enterococcus faecalis than in its absence [10]. Other studies present evidence that symbionts may provide nutritional benefits to their hosts by modifying plant defensive pathways, thus enabling the insects to overcome plant defenses, as was found for the chrysomelid beetles Diabrotica virgifera on maize [11] and Leptinotarsa decemlineata on Solanum lycopersicum [12].

Insects of the suborder Heteroptera, the true bugs, comprise around 40,000 species worldwide, some of which are important predators of a wide range of phytophagous pest insects $[8,13]$, and thus serve in biological control programs. Some others are important agricultural pests [14]. It has been known for over 50 years that heteropterans harbor symbiotic microorganisms; in many species, the ability to survive and reproduce on plant materials, prey items, or both resources in various mixtures has been attributed to the presence of symbiotic bacteria. Previous work suggests that the absence of symbionts of the genus Burkholderia in the broad-headed bugs Riptortus clavatus is responsible for a decrease in host fitness [15].

Within the Heteroptera, the nearly 10,000 species of the family Miridae have a diet breadth that includes various levels of specialization for herbivory, carnivory, or both (i.e., omnivory) [16]. Commercially used mirids, including Macrolophus pygmaeus and Nesidiocoris tenuis, are natural enemies of pestiferous arthropods and, as such, serve as a component of integrated pest management and biological control programs [17]. Macrolophus pygmaeus may also display phytophagous habits; it has been shown to successfully develop and oviposit, although at a lower rate, when feeding exclusively on leaves of tomato or eggplant [18]. In contrast, Nesidiocoris tenuis is able to feed on plants, but cannot complete its development in the absence of prey [19]. Although the involvement of bacteria in the omnivorous feeding habits of mirid bugs has yet to be investigated, some evidence supports this possibility. The omnivorous bug N. tenuis, for example, is known to harbor both Rickettsia and Wolbachia endosymbionts, and both have been found not only in host ovaries, but in the gut tissue as well [20]. Bacteria of these same genera have been reported by Machtelinckx et al. [21] in M. pygmaeus, a key natural enemy of various economically important agricultural pests of greenhouse vegetable crops [17]. Two Rickettsia species, R. bellii and R. limoniae, were identified by Machtelinckx et al. [21]. The commercial application of $M$. pygmaeus as a biological control agent has been limited by its potential to inflict significant damage by feeding on crop plants when prey becomes scarce [22]. Therefore, the overall objective of our ongoing research is to test the possible involvement of bacterial symbionts in the omnivorous feeding habits of M.pygmaeus. To this end, we (I) characterized the microbiome of 
M. pygmaeus, and (II) determined the identity and location of two Rickettsia species within its body. The results obtained are reported here.

\section{Material and Methods}

\subsection{Insect Rearing}

A culture of M. pygmaeus was established in February 2018 with 50 adults ( 30 females and 20 males) obtained from a commercial biological control company (BioBee Sde Eliyahu Ltd.). The bugs (Figure 1) were kept in ventilated cages in a climate chamber $\left(25 \pm 1^{\circ} \mathrm{C} 16: 8 \mathrm{~L}: \mathrm{D}\right)$ and offered symbiont-free frozen Ceratitis capitata eggs as prey, and tomato seedlings (cv. "Beefsteak", M. Ben-Shahar Ltd., Tel Aviv, Israel) as both food and oviposition substrate. The seedlings were replenished twice weekly.

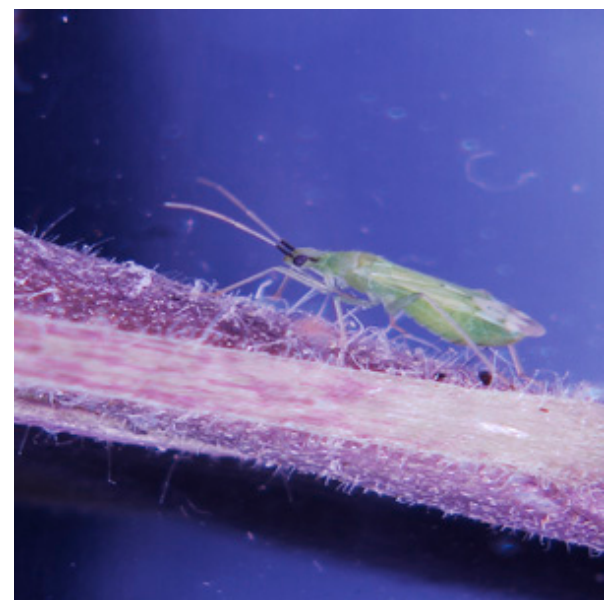

Figure 1. Adult female Macrolophus pygmaeus.

\subsection{Microbiota Characterization}

To identify the bacterial and fungal community in M. pygmaeus, total genomic DNA was extracted using SDS buffer, as described in [23], from five replicates, each consisting of 20 adult females. The DNA was used as a template for PCR amplification of the V4-V5 variable regions of microbial $16 \mathrm{~S}$ ribosomal RNA gene [24] using primers (forward 515F and reverse 926R) and the V7-V8 regions of the fungal 18S ribosomal RNA gene using primers FF390 and FR1 [25]. A two-stage targeted amplicon sequencing protocol was used as previously described [26]. Libraries were loaded onto a MiSeq v3 flow cell and sequenced $(2 \times 300$ paired end reads) using an Illumina MiSeq sequencer. PCR amplifications, library preparation, and sequencing were performed at the University of Illinois at Chicago Sequencing Core. Raw sequence data was processed with the Dada2 pipeline [27] in R using package 'dada2' (version 1.14.0). Fastq formatted reads were trimmed and filtered for low quality using the command 'filterAndTrim' with parameters $\operatorname{maxEE}=2, \operatorname{maxN}=0$, trimleft $=15$. Error rate estimation was carried out using 'learnerror' command with default parameters but the randomize parameter set to TRUE, in order to sample nucleotides and reads for model building randomly across all samples. The dada2 algorithm was subsequently implemented for error correction and a count table containing the amplicon sequence variants (ASVs), forward and reverse reads were merged using the 'mergePairs' command and counts per sample was produced. Suspected chimera was detected and filtered out using the command 'removeBimeraDenovo' using default parameters. For each ASV, taxonomy was inferred by alignment to the Silva non-redundant small subunit ribosomal RNA database (version 132, Ref. [28]) using command 'assignTaxonomy' with default parameters but setting minimum bootstrap confidence value to $80 \%$. For the bacterial dataset, non-bacterial ASVs, such as of mitochondrial, or chloroplast origin or unclassified ones, were removed. The resulting count matrix for each ASV in each sample and their taxonomic annotations were used for further analysis. 


\subsection{Screening for Rickettsia bellii and Rickettsia limoniae Prevalance}

To study the frequency of R. bellii and R. limoniae in M. pygmaeus, the symbionts were screened using PCR. Fourteen M. pygmaeus adults, seven females and seven males, were retrieved from the lab colony and placed in 70\% ethanol until processing. Individual insects were ground separately in $90 \mu \mathrm{L}$ lysis buffer [29] and checked by PCR with species-specific primers for the 16S rRNA gene of $R$. bellii and R. limoniae (Table 1). Negative controls contained sterilized water and DNA of Rickettsia-free sweet potato whiteflies (Bemisia tabaci). DNA of whiteflies harboring the bacterium served as a positive control for R. bellii, while the positive control for R. limoniae was the DNA used for deep sequencing, in which the bacterium has been identified. PCR procedures for adults were conducted in a final volume of $25 \mu \mathrm{L}$ containing $10 \mathrm{uL}$ G013-dye 2X PCR Taq MasterMix-abm, 10 pmol per microliter of each primer, $10 \mu \mathrm{L}$ DDW and $3 \mu \mathrm{L}$ of DNA. PCR was carried out under the following conditions; R. bellii: 2 min at $94{ }^{\circ} \mathrm{C}, 36$ cycles of $30 \mathrm{~s}$ at $92{ }^{\circ} \mathrm{C}, 30 \mathrm{~s}$ at $60{ }^{\circ} \mathrm{C}, 30 \mathrm{~s}$ at $72{ }^{\circ} \mathrm{C}$, and a final extension of $5 \mathrm{~min}$ at $72{ }^{\circ} \mathrm{C}$. R. limoniae: $2 \mathrm{~min}$ at $94{ }^{\circ} \mathrm{C}, 36$ cycles of $30 \mathrm{~s}$ at $92{ }^{\circ} \mathrm{C}, 30 \mathrm{~s}$ at $55^{\circ} \mathrm{C}, 30 \mathrm{~s}$ at $72{ }^{\circ} \mathrm{C}$, and a final extension of $5 \mathrm{~min}$ at $72{ }^{\circ} \mathrm{C}$. PCR products were stained with fluorescent dye ( $8 \mu \mathrm{L}$ SafeView ${ }^{\mathrm{TM}}$ nuclear stain), electrophoresed on $1.5 \%$ agarose gels $\times$ TAE-buffer, stained with ethidium bromide, and visualized under UV-light (Bio-Rad Gel Doc XR System, 254 nm).

Table 1. Primers and probes used to identify Rickettsia bellii and R. limoniae in M. pygmaeus.

\begin{tabular}{|c|c|c|c|}
\hline Targeted Gene/Probes & Name & Sequence & Reference \\
\hline \multicolumn{4}{|l|}{ Targeted Genes } \\
\hline $\begin{array}{c}\text { 16S rRNA gene of R. limoniae } \\
\text { and R. bellii }\end{array}$ & Rick-1F & 5'-ATACCGAGTGRGTGAYGAAG-3' & [21] \\
\hline 16S rRNA gene of $R$. limoniae & Ricklimoniae-F & 5'-CGGTACCTGACCAAGAAAGC-3' & [21] \\
\hline 16S rRNA gene of $R$. bellii & Rickbellii-R & 5'-TCCACGTCGCCGTCTTGC-3' & {$[30]$} \\
\hline 16S rRNA Rickettsia & $1513 R$ & 5'-ACGGYTACCTTGTTACGACTT-3' & [30] \\
\hline \multicolumn{4}{|l|}{ Probes } \\
\hline Rb1-Cy3 & R. bellii-specific probe & 5'-TCCACGTCGCCGTCTTGC-3' & [30] \\
\hline Rl1-Cy5 & R. limoniae-specific probe & 5'-GCTTTCTTGGTCAGGTACCG-3' & [21] \\
\hline
\end{tabular}

2.4. Location of R. bellii and R. limoniae in M. pygmaeus

\subsubsection{Morphology of the Digestive System}

To characterize the morphology of female and male digestive systems, over 50 adult females and 50 males of $M$. pygmaeus were dissected on microscope slides in physiological saline, using fine needles. Ovaries and guts were dissected under a stereoscope (Nikon SMZ-1000) by removing the head, anchoring the body, and gently pulling the edge of the abdomen until the ovaries and digestive system were revealed. They were photographed under a 3D digital microscope (Hirox RH-2000, Jyfel, Bâtiment A F-69760, Limonest, France).

\subsubsection{PCR for Ovaries and Digestive System}

To detect the presence of $R$. limoniae and R. bellii, nine females and nine males were dissected individually, as described above. PCR were performed separately for dissected ovaries and the digestive system, as described above, with the following alteration: ovaries and the digestive system were ground separately in $40 \mu \mathrm{L}$ of Lysis buffer. PCR were performed in $13 \mu \mathrm{L}$ final volume containing $5 \mu \mathrm{L}$ G013-dye 2X PCR Taq MasterMix-abm, 10 pmol per microliter of each primer, $5 \mu \mathrm{L}$ DDW, and $2 \mu \mathrm{L}$ of DNA. 


\subsubsection{Fluorescence in Situ Hybridization (FISH)}

To determine the location of the two dominant bacteria, R. limoniae and R. bellii, in the reproductive organs and digestive system, fluorescent in situ hybridization (FISH) was performed. The analysis was carried out following the protocol described by Gottlieb et al. [30] for whole mounted samples, with slight modifications. Each of over 50 ovaries and 50 digestive tracts were placed individually in a drop of 1X PBS under a stereomicroscope, fixed for $5 \mathrm{~min}$ in Carnoy's fixative (chloroform: ethanol: glacial acetic acid, 6:3:1), then washed twice in hybridization buffer (20 Mm TRIS-HCL pH 8.0; $0.9 \mathrm{M} \mathrm{NaCl} ; 0.01 \%$ SDS; 30\% Formamide [F9037] (Sigma-Aldrich Products Ltd., Rehovot, Israel) without probe, and then hybridized overnight in hybridization buffer with fluorescent probe at $25^{\circ} \mathrm{C}$. Two DNA probes used for the analysis were the R. bellii-specific probe CY3 and R. limoniae-specific probe CY5 (Table 1). A no-probe experiment and the hybridization of a digestive system were used as controls. Images were acquired using an OLYMPUS IX 81 (Japan) inverted laser scanning confocal microscope (FLUOVIEW 500) equipped with 405, 561, $640 \mathrm{~nm}$ laser lines, a UplanApo $10 \times / 0.4$ NA dry objective, and PlanApo $40 \times / 0.9$ NA and $60 \times / 1.0$ NA water immersion objectives. For DAPI; $4^{\prime}$, 6-diamidino-2-phenylindole is a fluorescent stain which binds preferentially to the AT-rich regions of dsDNA, $405 \mathrm{~nm}$ excitation light and a BA430-460 $\mathrm{nm}$ barrier filter were used; for the detection of fluorochrome CY3, $561 \mathrm{~nm}$ excitation light and a BA575-620 nm barrier filter were used. For the detection of fluorochrome CY5, a $640 \mathrm{~nm}$ laser line and a BA 660IF filter were used. When DAPI, CY3 and CY5 were detected in a single sample, a dichroic mirror 405/488/561/640 was used. In all cases where more than one dye was monitored, sequential acquisition was performed. Confocal optical sections were obtained at increments of $5 \mu \mathrm{m}, 1.3 \mu \mathrm{m}$ and $0.8 \mu \mathrm{m}$ for $\times 10, \times 40$ and $\times 60$ objectives, respectively.

\section{Results}

\subsection{Microbiota Characterization}

The bacterial data set originating from five samples (pools of 20 female bugs each), resulted in a total of 94,293 reads mapped to 28 ASVs which were further analyzed (Table S1). Three ASVs, two Rickettsia populations and one Wolbachia population dominated the M. pygmaeus microbiome with cumulative relative abundance values of $94.8-98.7 \%$ among the five replicates. The similarity between two Rickettsia ASV was $96 \%$ (390 of 407 nucleotides of pairwise aligned sequences), indicating that two separate species of Rickettsia, namely R. limoniae and R. bellii, occur in the studied M. pygmaeus population. Only five other ASVs were prevalent in all five samples and included different Actinobacteria. The remaining 20 ASVs included various Actinobacteria, Alphaproteobacteria, and Gammaproteobacteria, with prevalence of 2/5 (1 ASV) and 1/5 (19 ASVs) only (Figure 2 and Table S1). In the fungal dataset, most sequences were of host origin (94.4-98.0\%). The remaining sequences were assigned to 21 fungal ASVs, the majority of which belonged to Ascomycota (Table S2). Due to the low quantity of sequence data, fungi were not further analyzed. Moreover, the PCR performed with species-specific primers showed that all females and males of M. pygmaeus originating from the lab population harbored the two Rickettsia species.

\subsection{Location of R. bellii and R. limoniae in M. pygmaeus Body}

\subsubsection{Morphology of Digestive System}

Microscopic observations revealed the structural configuration of the ovaries (Figure 3A) and female and male guts (Figure 3B,C). While the female digestive system was longer and wider than that of the males, the alimentary tract of both sexes displayed similar division into morphologically distinct regions: the foregut, a tubular region directly connected to mouth; the first, anterior region of the midgut, which was large and sac-like; the second, tubular region of the midgut; the third midgut region, which was soft and moderately swollen; and the fourth, posterior, moderately swollen, region of the midgut that was connected to the hindgut at the joining site of the Malpighian tubules. 


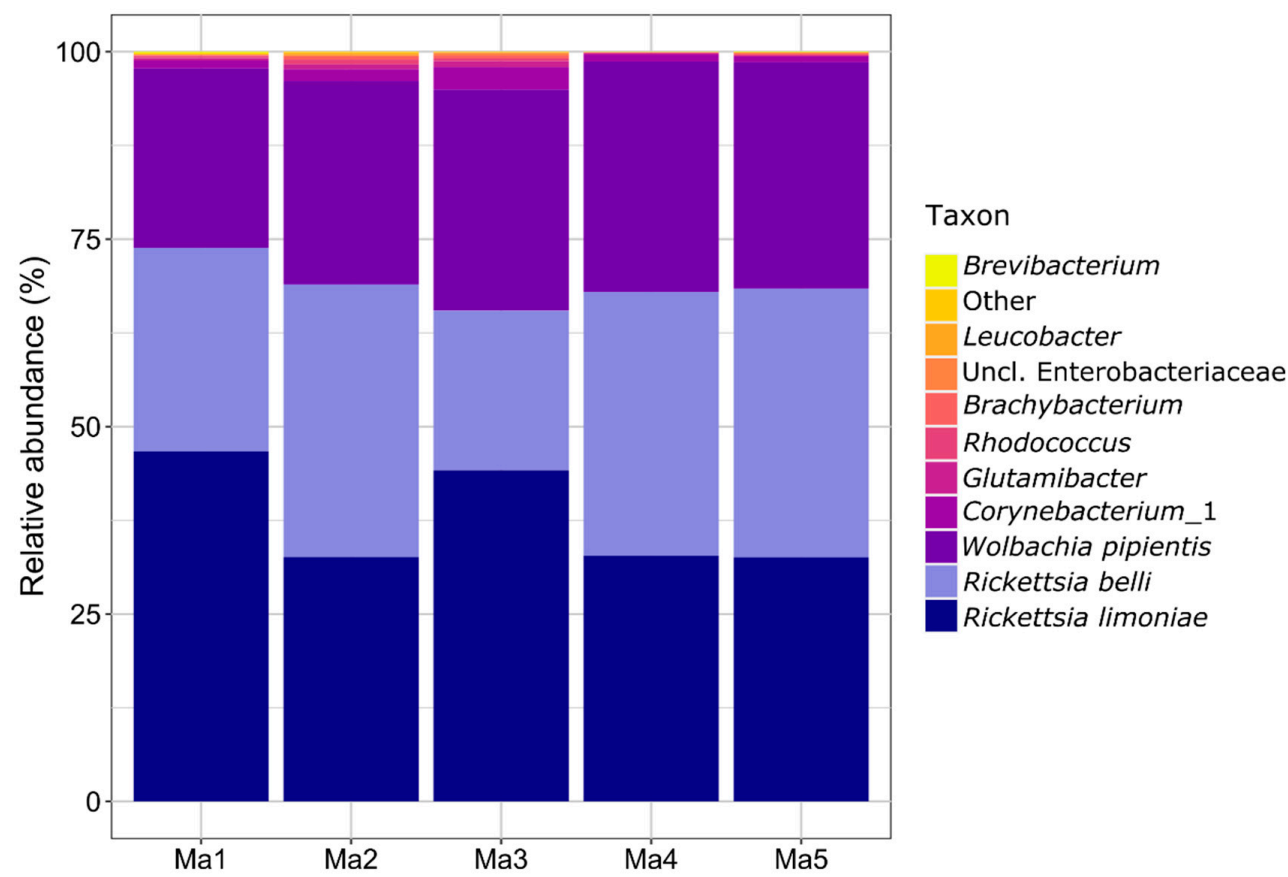

Figure 2. Relative abundance (\%) of bacterial microbiota composition of M. pygmaeus (five replicates, pools of 20 females each) based on amplicon sequencing of bacterial partial 16S rRNA gene (V4 region). Amplicon sequence variants were determined and quantified per sample using the Dada2 pipeline and taxonomically assigned by alignment to the Silva rRNA gene database (Table S1). Ma, M. pygmaeus.
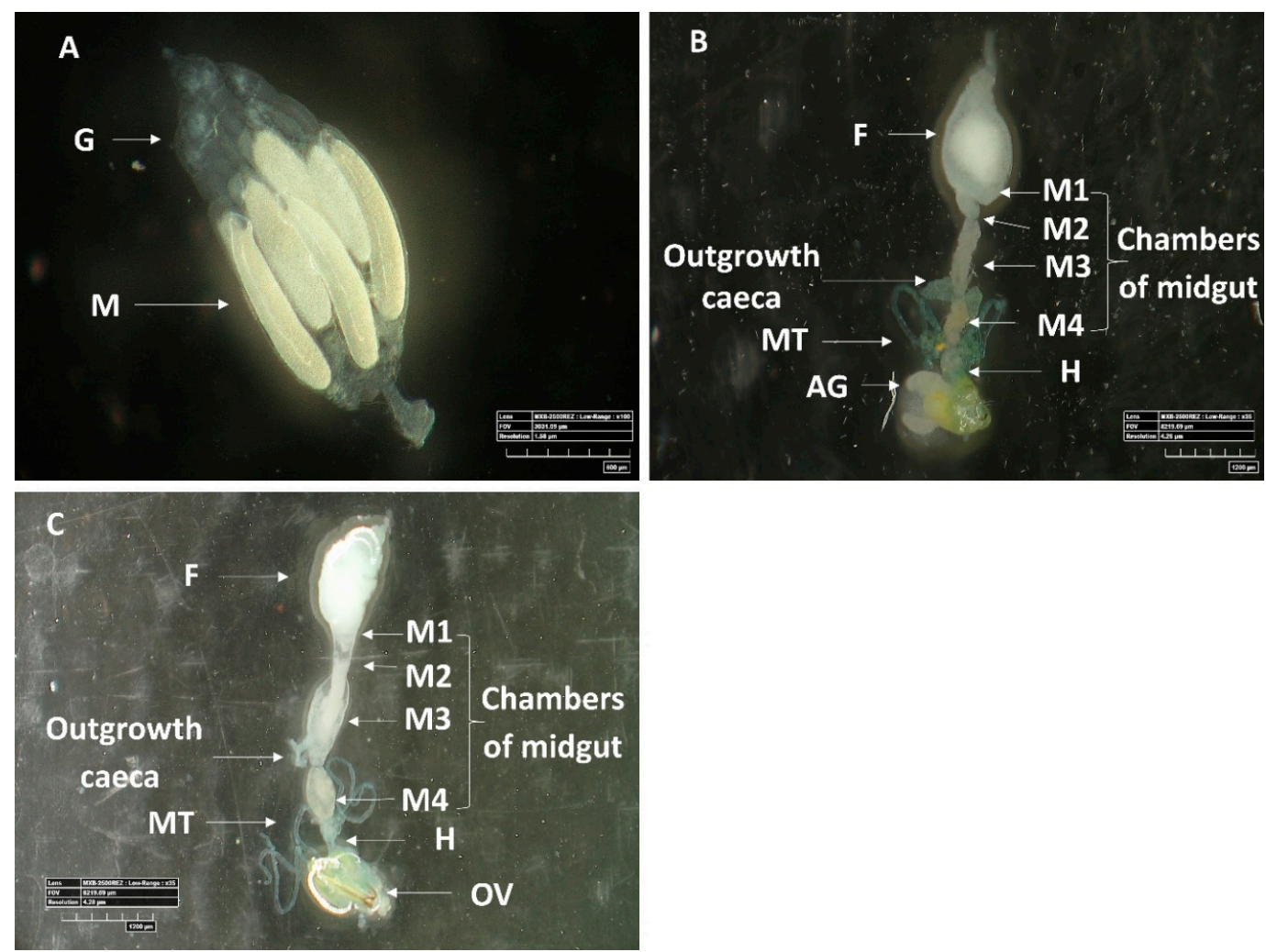

Figure 3. Images of M. pygmaeus ovary and male and female digestive systems. (A) An isolated ovary with several ovarioles; M, mature oocyte; G, Germarium, (B) Isolated male and (C) female digestive systems; F, foregut; M1, midgut first section; M2, midgut second section; M3, midgut third section (with outgrowth caeca); M4, midgut fourth section; MT, Malpighian tubules; H, hindgut; AG, accessory gland; OV, ovipositor. Images A-C were acquired by 3D digital microscopy using identical settings. 
Two specific outgrowth caeca which differ between females and males appear in the tissue of the third midgut region: in males, they appeared larger, abutting the digestive system, and were located at the posterior end of the third midgut region. In contrast, in females, the structures were smaller, not in direct full contact with the digestive system, and located at the posterior section of the third midgut region, but not at its end (Figure $3 \mathrm{~B}, \mathrm{C}$ ).

\subsubsection{PCR for Ovaries and Digestive System}

A diagnostic PCR using Rickettsia-specific primers on eighteen female and male digestive systems and ovaries showed that all M. pygmaeus individuals tested harbored both Rickettsia species.

\subsubsection{Fluorescence in Situ Hybridization}

In situ hybridization targeting bacterial $16 S$ rRNA confirmed the location of the two Rickettsia species within the ovaries and the digestive system. In the ovaries, R. bellii and R. limoniae were concentrated in the germarium, at the apical end of the ovarioles (Figure 4A). R. limoniae was scattered throughout the germarium, whereas $R$. bellii presented mainly in clusters (Figure 4B).
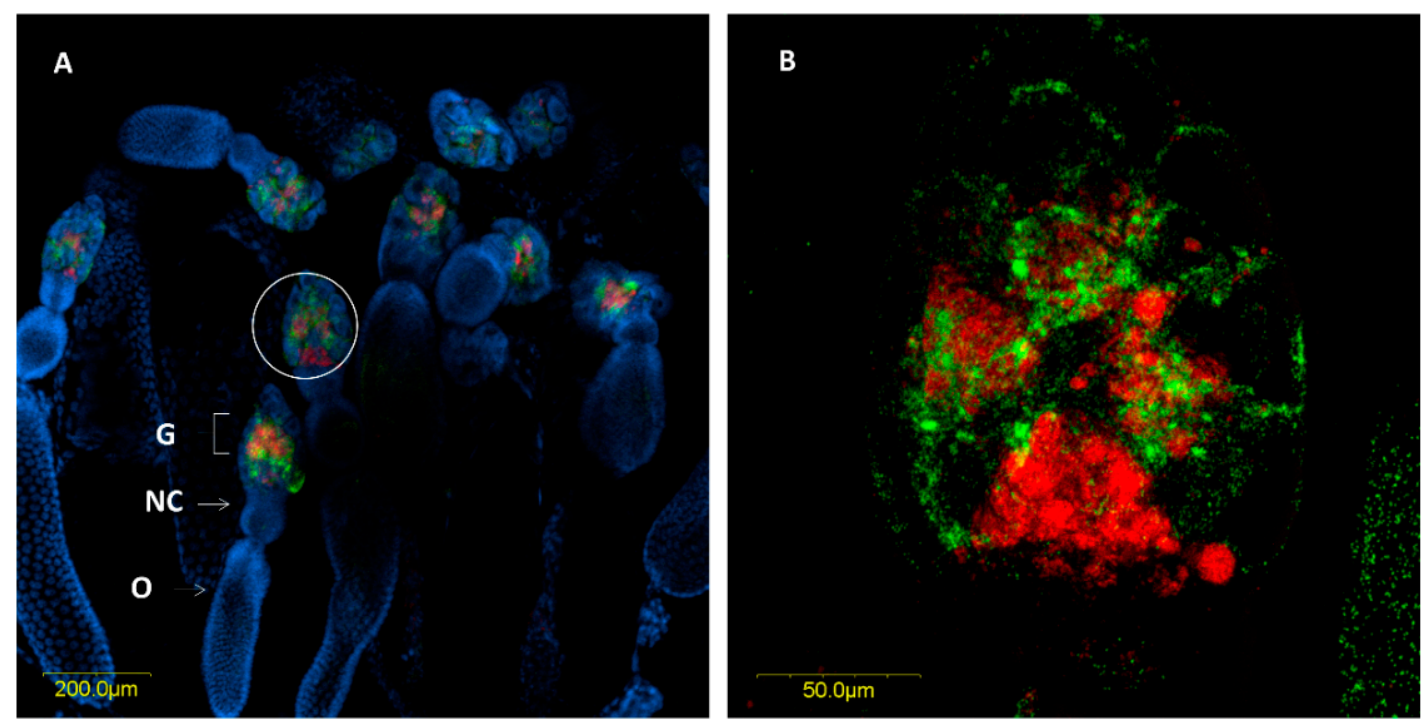

Figure 4. Fluorescence in situ hybridization (FISH) of M. pygmaeus ovarioles, R. bellii specific probes (red), R. limoniae specific probes (green), and DNA dye (blue). (A) Ovary with several ovarioles, $R$ bellii and $R$. limoniae are concentrated in the germarium; G, Germarium; NC, nurse cells; O, Oocyte. (B) Enlarged section of the germarium (white circle in A). Images A and B represent serial Z sections of $35 \mu \mathrm{m}$ and $13.6 \mu \mathrm{m}$, respectively.

FISH analysis revealed the presence of large numbers of the two Rickettsia species throughout the female and male digestive systems. In most cases, they were located in different specific host cells (hereafter, bacteriocytes) (Figures 5A and 6A). Infrequently, we found the two Rickettsia species sharing the same bacteriocyte (Figures 7 and 8 ). The bacteriocytes for $R$. limoniae were distributed throughout the entire digestive system, while $R$. bellii was located primarily in the foregut and midgut. FISH targeting bacterial $16 \mathrm{~S}$ rRNA visualized the $R$. limoniae and $R$. bellii bacteriocytes in the inner of the two outgrowth caeca regions, in the tissue of the third midgut section of females and males (Figures $5 \mathrm{~B}$ and $6 \mathrm{C}$ ). Furthermore, FISH analysis detected R. bellii and R. limoniae within the Malpighian tubules of females and males; $R$. limoniae was observed in all examined Malpighian tubules, whereas $R$. bellii was not always present (Figure 5C). 

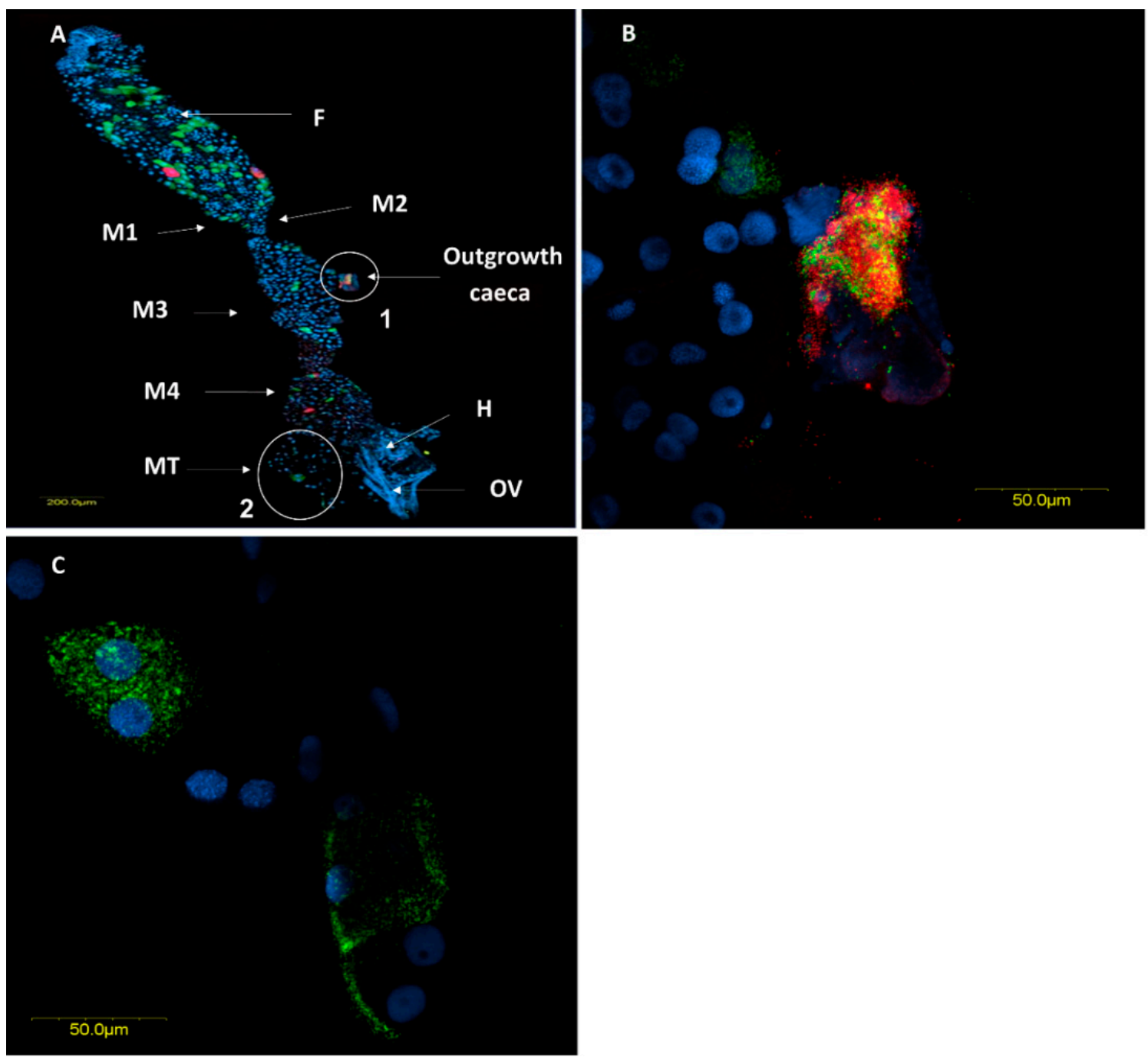

Figure 5. FISH of a female M. pygmaeus digestive system (DNA in blue). (A) The whole digestive system, R. bellii (red), R. limoniae (green). Reconstruction: three frames of the same gut; from $\mathrm{F}$ to M2 picture number 1, M3 picture number 2, M4 to OV picture number 3. (B) Enlarged section of the outgrowth caeca region, in the gut tissue of the third midgut section (white circle 1 in A). (C) Enlarged section of Malpighian tubules (white circle 2 in A). Images A number 1, A number 2, A number 3, B and C represent serial Z sections of $20 \mu \mathrm{m}, 55 \mu \mathrm{m}, 50 \mu \mathrm{m}, 12 \mu \mathrm{m}, 17 \mu \mathrm{m}$ respectively. F, foregut; M1, midgut first section; M2, midgut second section; M3, midgut third section (with outgrowth caeca); M4, midgut fourth section; MT, Malpighian tubules; H, hindgut; OV, ovipositor. 

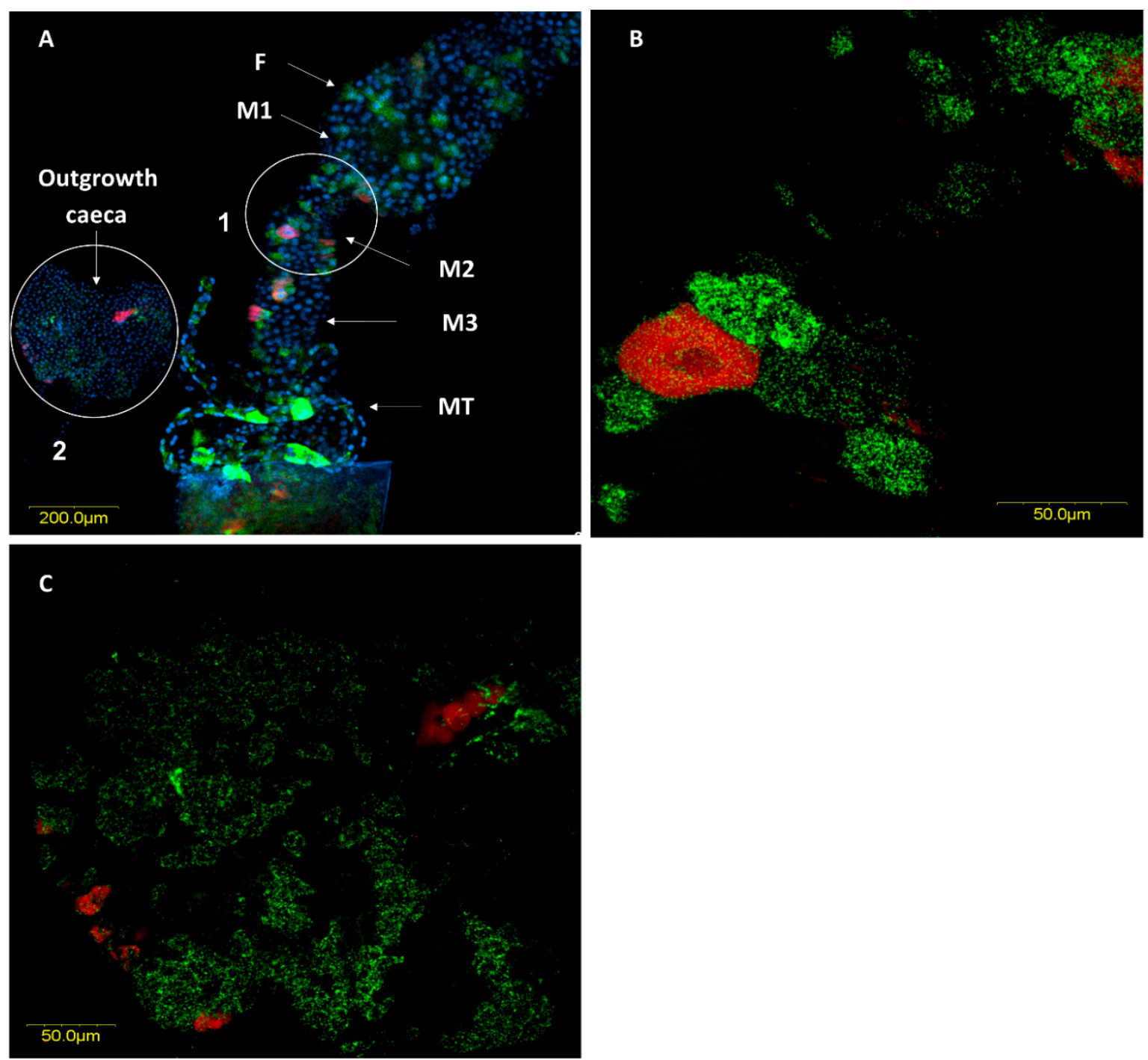

Figure 6. FISH of the male M. pygmaeus digestive system (DNA in blue). (A) The digestive system, $R$. bellii (red), R. limoniae (green), with two outgrowth caeca from the gut tissue of the third midgut section dissected aside (see circle 2). (B) Enlarged section from the midgut (see circle 1). (C) Enlarged section of the two outgrowth caeca (see circle 2). Images A, B and C represent serial Z sections of $35 \mu \mathrm{m}$, $8.8 \mu \mathrm{m}, 37.7 \mu \mathrm{m}$ respectively. F, foregut; M1, midgut first section; M2, midgut second section; M3, midgut third section; MT, Malpighian tubules. 

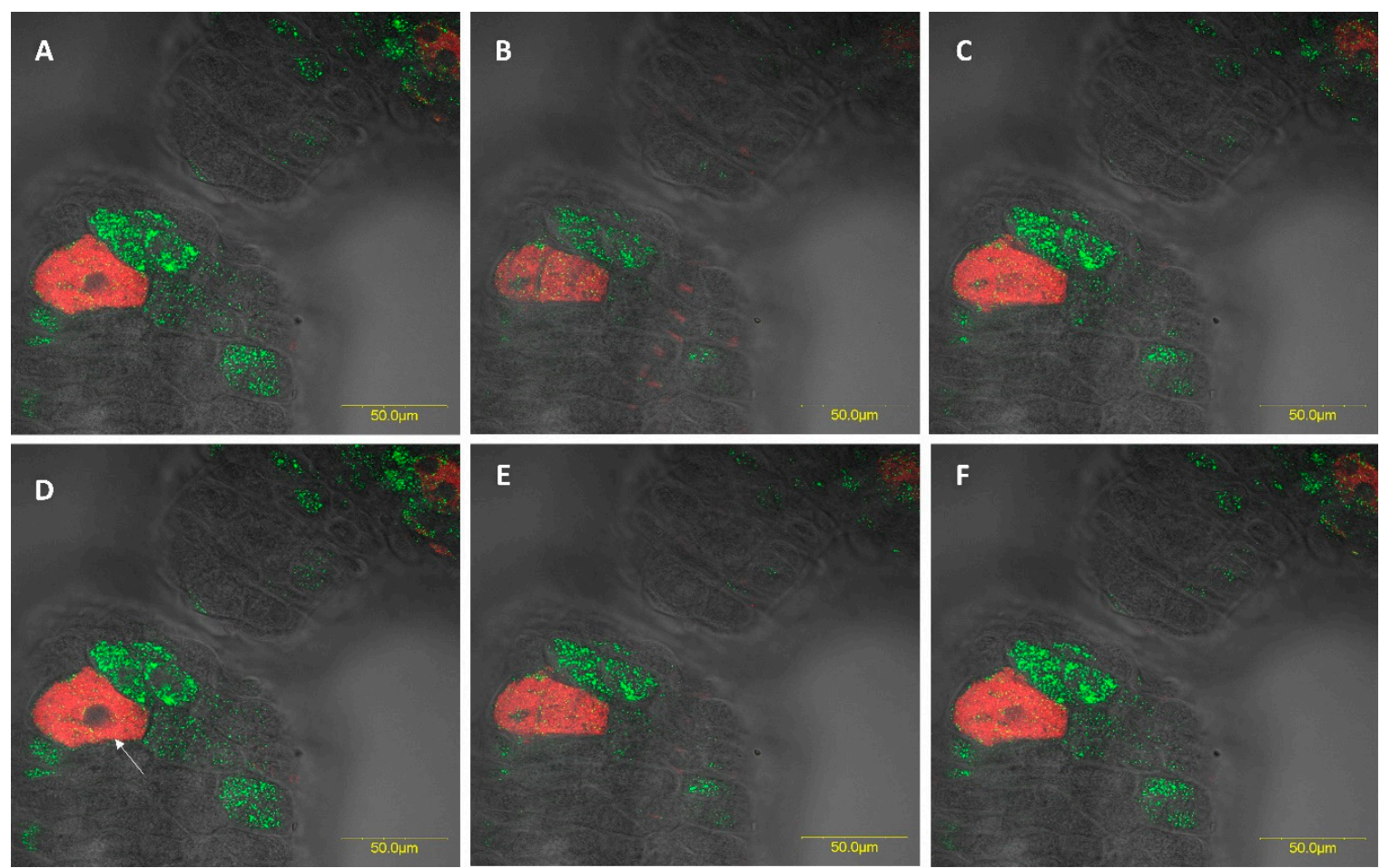

Figure 7. Z sections from part of male midgut of M. pygmaeus (circle 1 Figure 6A,B). Rickettsia bellii (red) and R. limoniae (green) can be seen to inhabit separate bacteriocytes in the gut epithelium, as well as occupying the same bacteriocyte, e.g., in Figure D (see arrow). (A-F) Serial Z-sections of 8.8 um (0.8 um increasement).
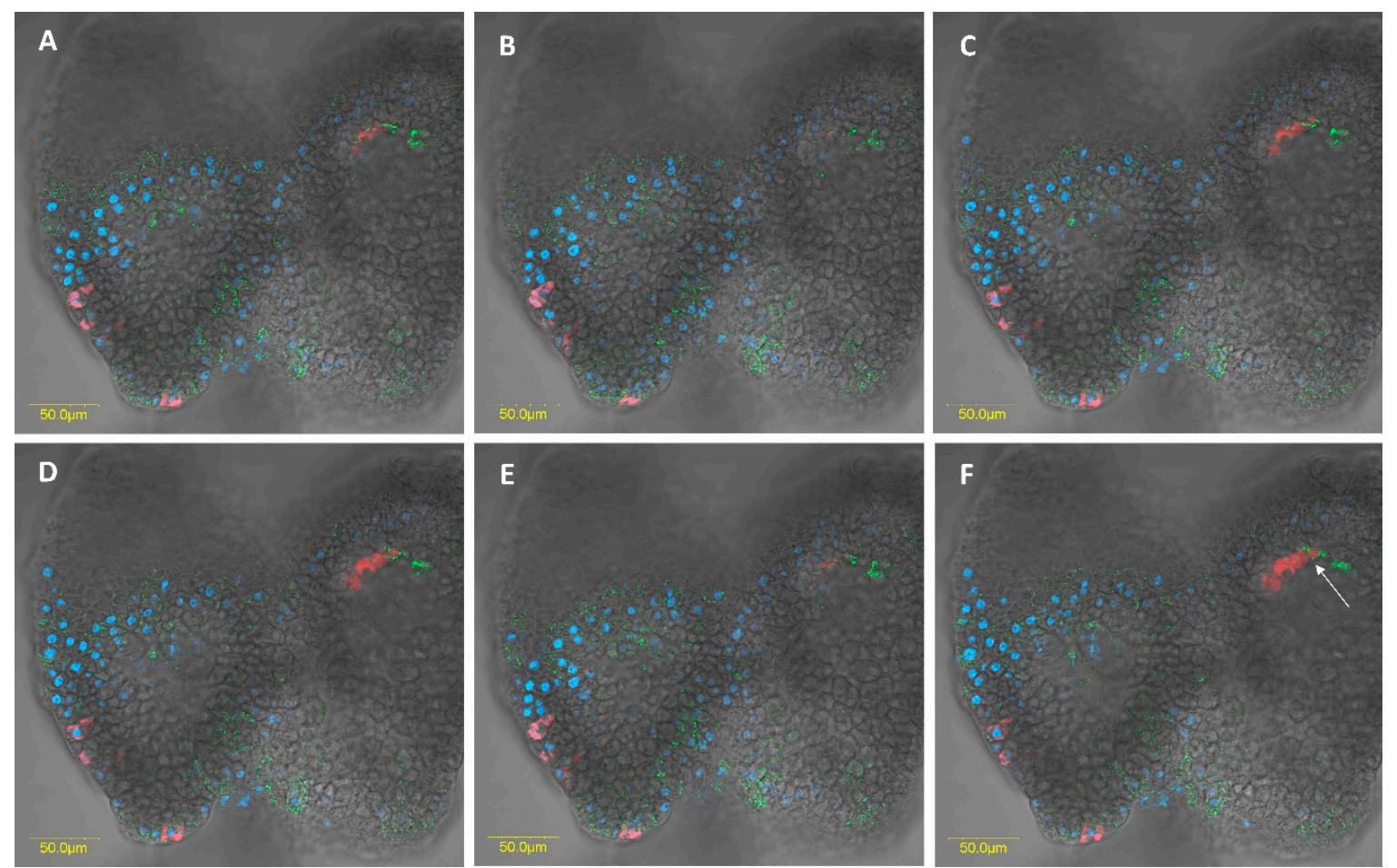

Figure 8. Z sections of two male outgrowth caeca (circle 2 Figure 6C) DNA (blue). R. bellii (red), $R$. limoniae (green) can be seen to inhabit separate bacteriocytes, as well as occupy the same bacteriocyte in the outgrowth caeca epithelium, e.g., in Figure F, see arrow. (A-F) Serial Z-sections of 37.7 um (1.3 um increasement). 


\section{Discussion}

Bioinformatic analysis in this study revealed that the microbial community associated with a laboratory strain of Macrolophus pygmaeus is composed of three dominant endosymbionts: Wolbachia sp., Rickettsia limoniae and $R$. bellii. An earlier phylogenetic analysis similarly demonstrated that the two Rickettsia species in M. pygmaeus are related to two different clades [21]. One falls within the 'Bellii' group, together with Rickettsia reported from several agricultural pests, such as the two-spotted spider mite (Tetranychus urticae), the pea aphid (Acyrthosiphon pisum), and the sweet potato whitefly (Bemisia tabaci). The second Rickettsia belongs to the 'limoniae' group, which has been reported from the microbiome of non-agricultural insects including the cranefly Limonia chorea [31]. The observed similarities in symbionts among arthropod species may suggest that bacteria undergo horizontal transfer between species in the environment. Such a transfer may occur via feeding; omnivorous species such as M. pygmaeus may acquire the symbionts directly by consuming infected prey or indirectly by feeding on plants shared with other phytophagous insects. Likewise, other species that feed on the same host plants might subsequently take up micro-organisms transferred by the bug to the plants by way of its piercing-sucking mouthparts. Caspi-Fluger et al. [32] had demonstrated such horizontal transmission of Rickettsia between two different whitefly species, through their shared cotton host plants. A similar through-the-plant transmission of intracellular bacteria such as, Rickettsia, Wolbachia, and Cardinium, was reviewed by Chrostek et al. [33] in Euscelidius variegatus leafhoppers. In addition, symbionts may be transferred between hosts by their shared parasitoids. For example, Hamiltonella defensa and Regiella insecticola may be transferred between aphid hosts by parasitoid wasps [34].

Machtelinckx et al. [21] demonstrated the presence of Wolbachia and the two Rickettsia species in the ovarioles of M. pygmaeus, indicating the presence of vertical transmission. Here, we described each Rickettsia species and demonstrated that both are found in the germaria at the tip of the ovarioles, but each species had a unique distribution pattern: while $R$. limoniae was scattered throughout the germarium, R. bellii appeared mainly in clusters. Although we did not observe Rickettsia in the oocytes, the germarium can be an infection zone of Rickettsia for further transmission into the oocytes, as described in the bulrush bug, Chilacis typhe [35]. It is thus possible that oocyte infection occurs at a later stage of oocyte maturation, before fertilization and deposition. Alternatively, Rickettsia had been shown to invade the oocytes of Bemisia tabaci whiteflies during early developmental stages, but is mostly excluded from the oocytes when eggs mature [36].

Many members of the suborder Heteroptera have established relationships with microbes, which inhabit specific outgrowths of the midgut caeca. Mirids have been thought to lack these caeca [16,37], but in this study, two specific outgrowths of the caeca were clearly in evidence in the third midgut region. They differed in appearance between males and females. To our knowledge, this is the first report of such structures in the Miridae. A possible nutritional function of these caeca in M. pygmaeus is suggested by the presence of bacteriocytes that harbor either R. bellii or R. limonia, with a few bacteriocytes containing both species.

While Wolbachia is known to induce strong cytoplasmic incompatibility in M. pygmaeus and is virtually absent from the digestive system [21,38], the role of Rickettsia in the biology of this bug is mostly unknown. As the long-term objective of our study is to test the involvement of bacterial symbionts in $M$. pygmaeus diet, we first determined the tissue localization and cellular pattern of the two Rickettsia species in the alimentary canal of males and females.

Finding both Rickettsia species in M. pygmaeus Malpighian tubules may be indicative of a symbiont hosting role of these organs, as was found for nutritional symbionts in ticks [39]. Likewise, Malpighian tubules harbor endosymbionts that appear to contribute to the physiological function of leaf and bark beetles [40]. For instance, Macroplea appendiculata and M. muticare reed beetles appear to construct underwater cocoons by using the secretion of two bacteria endosymbionts that reside in cells of their Malpighian tubule [41]. 
Microbes have been reported to be established in both mid- and hind-gut epithelia of arthropods, where the highly convoluted plasma membranes of the cells present a large area for extensive contact with microbial surfaces [37]. Symbionts have in fact been reported in the mid-gut of Heteroptera species belonging to several families, whether in crypts in the posterior region of the mid-gut, in the lumen or on the epithelial walls of the mid-gut itself, or in specialized bacteriomes [42-44]. Rickettsia were reported in the nuclei and cytoplasm of midgut epithelial cells of the plant bug Stenotzls birtotatus [45], in the midgut cells and lumen of Bemisia tabaci [30], and in the lumen along the digestive tract of Nesidiocoris tenuis [20]. These symbionts appear to enhance the fitness of their heteropteran hosts, may be through nutritional function; the absence of symbionts resulted in retarded growth, increased mortality, and/or sterility [42,46]. Furthermore, Feldhaar et al. [47] demonstrated that Blochmannia, an intracellular midgut endosymbiont of Camponotus floridanus, provides these ants essential amino acids, and that it may also play a role in nitrogen recycling via its functional urease. Interestingly, removal of all three symbionts from $M$. pygmaeus resulted in higher sensitivity to freezing conditions [48]. It is not yet clear which of the symbionts causes this negative effect by its absence.

FISH results showed the presence of bacteriocyte-like cells within the digestive system of M. pygmaeus. Each of the Rickettsia species was found to be hosted in a different bacteriocyte within the digestive gut compartments. In rare instances, the two Rickettsia species were found to share the same bacteriocyte. The intracellular arena hypothesis, which states that genetic exchange can occur in communities of bacterial endosymbionts that infect the same cellular environment of a shared host, is supported by documented findings from the dipteran Drosophila simulans and the hymenopteran Nasonia vitripennis [49]. To our knowledge, however, this is the first report of two Rickettsia species sharing the same bacteriocyte in insects. The association of different bacterial species together in the same host cell may suggest that each symbiont induces unique effects, and that they may act synergistically [50]. In the context of multiple infections with vertically transmitted symbionts, the bacterial partners are limited to a restricted shared environment and the evolutionary fate of all partners is tightly linked. If the transmission of each partner depends on the transmission of the others, cooperative interactions and communication among symbionts can be expected [50]. However, since the cohabitation of a single bacteriocyte by the two Rickettsia species was rare in the studied system, it may indicate antagonistic interactions through competitive displacement [50,51]. Notably, $R$. limoniae was more broadly distributed along the host digestive system than $R$. bellii and appeared in a scattered pattern compared to the clustering of $R$. bellii. This may suggest a different interaction with the host cellular environment and may be the result of different host control mechanisms over its symbionts.

\section{Conclusions}

In conclusion, our results describe the presence of two congeneric Rickettsia species in M. pygmaeus ovaries and alimentary canal. That unique distribution pattern suggests a possible nutritional benefit conferred by these endosymbionts on their omnivorous host, via either complementary or synergistic interaction.

Supplementary Materials: The following are available online at http://www.mdpi.com/2075-4450/11/8/530/s1. Table S1: amplicon sequence variants (ASVs) determined for M. pygmaeus population from partial 16S rRNA amplicon sequencing. Table S2: Amplicon sequence variants (ASVs) determined for M. pygmaeus population from partial 18S rRNA amplicon sequencing.

Author Contributions: Conceptualization, E.Z.-F. and M.C.; Microbiota data analysis, M.L.; conducted all lab work, analyzed data, prepared original draft, M.D.; Image scanning by confocal microscope, E.B.; wrote, reviewed and edited, M.D., E.Z.-F., M.C. and Y.G. All authors have read and agreed to the published version of the manuscript.

Funding: This project was partially funded by the Chief Scientist's Office of the Ministry of Agriculture and Rural Development in Israel, Grant number 20-02-0092. 
Acknowledgments: We thank Murad Ghanim, Netta Mozes-Daube and Shira Gal for technical help. Thanks also to Ruth Ann Yonah for her valuable comments on drafts of the manuscript. Lastly, we thank BioBee Sde Eliyahu Ltd., for providing us with a laboratory strain of M. pygmaeus.

Conflicts of Interest: The authors declare no conflict of interest.

\section{References}

1. Singh, S.; Arya, S.K.; Kaur, G.; Saxena, G.; Verma, P.C. Role of endosymbionts in nutritional uptake of sap sucking insects. In Molecular Approaches in Plant Biology and Environmental Challenges. Energy, Environment, and Sustainability; Singh, S.P., Upadhyay, S.K., Pandey, A., Kumar, S., Eds.; Springer: Singapore, 2019; pp. 487-499.

2. Oliver, K.M.; Degnan, P.H.; Burke, G.R.; Moran, N.A. Facultative symbionts in aphids and the horizontal transfer of ecologically important traits. Annu. Rev. Entomol. 2010, 55, 247-266. [CrossRef] [PubMed]

3. Douglas, A.E. Multiorganismal insects: Diversity and function of resident microorganisms. Annu. Rev. Entomol. 2015, 60, 17-34. [CrossRef] [PubMed]

4. Shropshire, J.D.; Bordenstein, S.R. Speciation by symbiosis: The microbiome and behavior. MBio 2016, 7, e01785-15. [CrossRef] [PubMed]

5. Russell, J.A.; Dubilier, N. Nature's microbiome: Introduction. Mol. Ecol. 2014, 23, 1225-1237. [CrossRef] [PubMed]

6. Gottlieb, Y.; Perlman, S.J.; Chiel, E.; Zchori-Fein, E. Rickettsia get around. In Manipulative Tenants: Bacteria Associated with Arthropods; Zchori-Fein, E., Bourtzis, K., Eds.; CRC Press: Boca Raton, FL, USA, 2011; pp. 191-206.

7. Salem, H.; Florez, L.; Gerardo, N.; Kaltenpoth, M. An out-of-body experience: The extracellular dimension for the transmission of mutualistic bacteria in insects. Proc. R. Soc. B Biol. Sci. 2015, 282, 20142957. [CrossRef]

8. Sudakaran, S.; Kost, C.; Kaltenpoth, M. Symbiont acquisition and replacement as a source of ecological innovation. Trends Microbiol. 2017, 25, 375-390. [CrossRef]

9. Hansen, A.K.; Moran, N.A. The impact of microbial symbionts on host plant utilization by herbivorous insects. Mol. Ecol. 2014, 23, 1473-1496. [CrossRef]

10. Schmid, R.B.; Lehman, R.M.; Brözel, V.S.; Lundgren, J.G. An indigenous gut bacterium, Enterococcus faecalis (Lactobacillales: Enterococcaceae), increases seed consumption by Harpalus pensylvanicus (Coleoptera: Carabidae). Florida Entomol. 2014, 97, 575-584. [CrossRef]

11. Barr, K.L.; Hearne, L.B.; Briesacher, S.; Clark, T.L.; Davis, G.E. Microbial symbionts in insects influence down-regulation of defense genes in maize. PLoS ONE 2010, 5, e11339. [CrossRef]

12. Chung, S.H.; Rosa, C.; Scully, E.D.; Peiffer, M.; Tooker, J.F.; Hoover, K.; Luthe, D.S.; Felton, G.W. Herbivore exploits orally secreted bacteria to suppress plant defenses. Proc. Natl. Acad. Sci. USA 2013, 110, 15728-15733. [CrossRef]

13. Krinsky, W.L. Hemiptera (True Bugs). In Medical and Veterinary Entomology; Mullen, G.R., Durden, L.A., Eds.; Academic Press: New Haven, CT, USA, 2019; pp. 107-127.

14. Schaefer, C.W.; Panizzi, A.R. Heteroptera of Economic Importance; Schaefer, C.W., Panizzi, A.R., Eds.; CRC Press: Washington, DC, USA, 2000; pp. 3-7.

15. Kikuchi, Y.; Hosokawa, T.; Fukatsu, T. Insect-microbe mutualism without vertical transmission: A stinkbug acquires a beneficial gut symbiont from the environment every generation. Appl. Environ. Microbiol. 2007, 73, 4308-4316. [CrossRef] [PubMed]

16. Wheeler, A.G. Biology of the Plant Bugs (Hemiptera: Miridae): Pests, Predators, Opportunists, 1st ed.; Cornell University Press: Ithaca, NY, USA, 2001; pp. 1-4.

17. Perdikis, D.; Fantinou, A.A.; Lykouressis, D.P. Enhancing pest control in annual crops by conservation of predatory Heteroptera. Biol. Control 2011, 59, 13-21. [CrossRef]

18. Perdikis, D.; Lykouressis, D. Effects of various items, host plants, and temperatures on the development and survival of Macrolophus pygmaeus Rambur (Hemiptera: Miridae). Biol. Control 2000, 17, 55-60. [CrossRef]

19. Urbaneja, A.; Tapia, G.; Stansly, P. Influence of host plant and prey availability on developmental time and survivorship of Nesidiocoris tenius (Het.: Miridae). Biocontrol Sci. Technol. 2005, 15, 513-518. [CrossRef]

20. Caspi-Fluger, A.; Inbar, M.; Steinberg, S.; Friedmann, Y.; Freund, M.; Mozes-Daube, N.; Zchori-Fein, E. Characterization of the symbiont Rickettsia in the mirid bug Nesidiocoris tenuis (Reuter) (Heteroptera: Miridae). Bull. Entomol. Res. 2014, 104, 681-688. [CrossRef] [PubMed] 
21. MacHtelinckx, T.; Van Leeuwen, T.; Van De Wiele, T.; Boon, N.; De Vos, W.H.; Sanchez, J.A.; Nannini, M.; Gheysen, G.; De Clercq, P. Microbial community of predatory bugs of the genus Macrolophus (Hemiptera: Miridae). BMC Microbiol. 2012, 12, 1-14.

22. Castañé, C.; Arnó, J.; Gabarra, R.; Alomar, O. Plant damage to vegetable crops by zoophytophagous mirid predators. Biol. Control 2011, 59, 22-29. [CrossRef]

23. Chen, H.; Rangasamy, M.; Tan, S.Y.; Wang, H.; Siegfried, B.D. Evaluation of five methods for total DNA extraction from western corn rootworm beetles. PLoS ONE 2010, 5, e11963. [CrossRef]

24. Walters, W.; Hyde, E.R.; Berg-Lyons, D.; Ackermann, G.; Humphrey, G.; Parada, A.; Gilbert, J.A.; Jansson, J.K.; Caporaso, J.G.; Fuhrman, J.A.; et al. Improved bacterial 16S rRNA gene (V4 and V4-5) and fungal internal transcribed spacer marker gene primers for microbial community surveys. mSystems 2015, 1, e0009-15. [CrossRef]

25. Vainio, E.J.; Hantula, J. Direct analysis of wood-inhabiting fungi using denaturing gradient gel electrophoresis of amplified ribosomal DNA. Mycol. Res. 2000, 104, 927-936. [CrossRef]

26. Jiang, P.; Green, S.J.; Chlipala, G.E.; Turek, F.W.; Vitaterna, M.H. Reproducible changes in the gut microbiome suggest a shift in microbial and host metabolism during spaceflight. Microbiome 2019, 7, 1-18. [CrossRef] [PubMed]

27. Callahan, B.J.; McMurdie, P.J.; Rosen, M.J.; Han, A.W.; Johnson, A.J.A.; Holmes, S.P. DADA2: High-resolution sample inference from Illumina amplicon data. Nat. Methods 2016, 13, 581-583. [CrossRef] [PubMed]

28. Quast, C.; Pruesse, E.; Yilmaz, P.; Gerken, J.; Schweer, T.; Yarza, P.; Peplies, J.; Glöckner, F.O. The SILVA ribosomal RNA gene database project: Improved data processing and web-based tools. Nucleic Acids Res. 2012, 41, 590-596. [CrossRef] [PubMed]

29. Frohlich, D.R.; Torres-Jerez, I.; Bedford, I.D.; Markham, P.G.; Brown, J.K. A phylogeographical analysis of the Bemisia tabaci species complex based on mitochondrial DNA markers. Mol. Ecol. 1999, 8, 1683-1691. [CrossRef]

30. Gottlieb, Y.; Ghanim, M.; Chiel, E.; Gerling, D.; Portnoy, V.; Steinberg, S.; Tzuri, G.; Horowitz, A.R.; Belausov, E.; Mozes-Daube, N.; et al. Identification and localization of a Rickettsia sp. in Bemisia tabaci (Homoptera: Aleyrodidae). Environ. Microbiol 2006, 72, 3646-3652. [CrossRef]

31. Perlman, S.J.; Hunter, M.S.; Zchori-Fein, E. The emerging diversity of Rickettsia. Proc. R. Soc. B Biol. Sci. 2006, 273, 2097-2106. [CrossRef]

32. Caspi-Fluger, A.; Inbar, M.; Mozes-Daube, N.; Katzir, N.; Portnoy, V.; Belausov, E.; Hunter, M.S.; Zchori-Fein, E. Horizontal transmission of the insect symbiont Rickettsia is plant-mediated. Proc. R. Soc. B Biol. Sci. 2012, 279, 1791-1796. [CrossRef]

33. Chrostek, E.; Pelz-Stelinski, K.; Hurst, G.D.D.; Hughes, G.L. Horizontal transmission of intracellular insect symbionts via plants. Front. Microbiol. 2017, 8, 1-8. [CrossRef]

34. Gehrer, L.; Vorburger, C. Parasitoids as vectors of facultative bacterial endosymbionts in aphids. Biol. Lett. 2012, 8, 613-615. [CrossRef]

35. Kuechler, S.M.; Dettner, K.; Kehl, S. Characterization of an obligate intracellular bacterium in the midgut epithelium of the bulrush bug Chilacis typhae (Heteroptera, Lygaeidae, Artheneinae). Appl. Environ. Microbiol. 2011, 77, 2869-2876. [CrossRef]

36. Brumin, M.; Levy, M.; Ghanim, M. Transovarial transmission of Rickettsia spp. and organ-specific infection of the Whitefly Bemisia tabaci. Appl. Environ. Microbiol. 2012, 78, 5565-5574. [CrossRef] [PubMed]

37. Nardi, J.B.; Miller, L.A.; Bee, C.M. Interfaces between microbes and membranes of host epithelial cells in hemipteran midguts. J. Morphol. 2019, 280, 1046-1060. [CrossRef] [PubMed]

38. Machtelinckx, T.; Van Leeuwen, T.; Vanholme, B.; Gehesquière, B.; Dermauw, W.; Vandekerkhove, B.; Gheysen, G.; De Clercq, P. Wolbachia induces strong cytoplasmic incompatibility in the predatory bug Macrolophus pygmaeus. Insect Mol. Biol. 2009, 18, 373-381. [CrossRef] [PubMed]

39. Duron, O.; Morel, O.; Noël, V.; Buysse, M.; Binetruy, F.; Lancelot, R.; Loire, E.; Ménard, C.; Bouchez, O.; Vavre, F.; et al. Tick-bacteria mutualism depends on B vitamin synthesis pathways. Curr. Biol. 2018, 28, 1896-1902.e5. [CrossRef] [PubMed]

40. Perotti, M.A.; Clarke, H.K.; Turner, B.D.; Braig, H.R. Rickettsia as obligate and mycetomic. FASEB J. 2006, 20, 2372-2374. [CrossRef] 
41. Kölsch, G.; Matz-Grund, C.; Pedersen, B.V. Ultrastructural and molecular characterization of endosymbionts of the reed beetle genus Macroplea (Chrysomelidae, Donaciinae), and proposal of "Candidatus Macropleicola appendiculatae" and "Candidatus Macropleicola muticae". Can. J. Microbiol. 2009, 55, 1250-1260. [CrossRef]

42. Kikuchi, Y.; Hosokawa, T.; Nikoh, N.; Meng, X.Y.; Kamagata, Y.; Fukatsu, T. Host-symbiont co-speciation and reductive genome evolution in gut symbiotic bacteria of acanthosomatid stinkbugs. BMC Biol. 2009, 7, 1-22. [CrossRef]

43. Kaltenpoth, M.; Winter, S.A.; Kleinhammer, A. Localization and transmission route of Coriobacterium glomerans, the endosymbiont of pyrrhocorid bugs. FEMS Microbiol. Ecol. 2009, 69, 373-383. [CrossRef]

44. Kuechler, S.M.; Renz, P.; Dettner, K.; Kehl, S. Diversity of symbiotic organs and bacterial endosymbionts of lygaeoid bugs of the families Blissidae and Lygaeidae (Hemiptera: Heteroptera: Lygaeoidea). Appl. Environ. Microbiol. 2012, 78, 2648-2659. [CrossRef]

45. Chang, K.P.; Musgrave, A.J. Ultrastructure of Rickettsia-like microorganisms in the midgut of a plant bug, Stenotus binotatus Jak. (Heteroptera: Miridae). Can. J. Microbiol. 1970, 16, 621-622. [CrossRef]

46. Fukatsu, T.; Hosokawa, T. Capsule-transmitted gut symbiotic bacterium of the Japanese common plataspid stinkbug, Megacopta punctatissima. Appl. Environ. Microbiol. 2002, 68, 389-396. [CrossRef] [PubMed]

47. Feldhaar, H.; Straka, J.; Krischke, M.; Berthold, K.; Stoll, S.; Mueller, M.J.; Gross, R. Nutritional upgrading for omnivorous carpenter ants by the endosymbiont Blochmannia. BMC Biol. 2007, 5, 48.

48. Maes, S.; Machtelinckx, T.; Moens, M.; Grégoire, J.C.; De Clercq, P. The influence of acclimation, endosymbionts and diet on the supercooling capacity of the predatory bug Macrolophus pygmaeus. BioControl 2012, 57, 643-651. [CrossRef]

49. Bordenstein, S.R.; Wernegreen, J.J. Bacteriophage flux in endosymbionts (Wolbachia): Infection frequency, lateral transfer, and recombination rates. Mol. Biol. Evol. 2004, 21, 1981-1991.

50. Vautrin, E.; Vavre, F. Interactions between vertically transmitted symbionts: Cooperation or conflict? Trends Microbiol. 2009, 17, 95-99.

51. Vautrin, E.; Genieys, S.; Charles, S.; Vavre, F. Do vertically transmitted symbionts co-existing in a single host compete or cooperate? A modelling approach. Evol. Biol. 2008, 21, 145-161.

(C) 2020 by the authors. Licensee MDPI, Basel, Switzerland. This article is an open access article distributed under the terms and conditions of the Creative Commons Attribution (CC BY) license (http://creativecommons.org/licenses/by/4.0/). 